\title{
Canon minero y ciclo político presupuestal en las municipalidades distritales del Perú, 2002-2011
}

\author{
Carol Pebe, Norally Radas y Javier Torres
}

\section{Resumen}

El objetivo del presente estudio es determinar si el acceso a un volumen mayor de fondos provenientes del canon minero afecta al monto del gasto de capital efectuado por los alcaldes distritales en los años electorales. Desde la perspectiva del ciclo político presupuestal, se analiza el efecto de los ciclos electorales del Perú en la inversión pública distrital (de 2002 a 2011) y su relación con el canon minero, mediante un modelo de panel de efectos fijos. Los resultados muestran que existe un efecto diferenciado del canon minero en el $20 \%$ de los distritos que reciben un mayor volumen de canon minero. Sin embargo, en términos generales, no hay una marcada ciclicidad entre el gasto de capital de esas municipalidades y los años electorales.

\section{Palabras clave}

Minería, ingresos fiscales, gobierno local, gobierno municipal, gastos públicos, ejecución presupuestaria, aspectos políticos, elecciones, Perú

\section{Clasificación JEL}

D72, P16, H72, Q32, Q33

\section{Autores}

Carol Pebe Bernal es Licenciada en Economía de la Universidad del Pacífico del Perú. Correo electrónico: carolpebe@gmail.com.

Norally Radas Kovalchuk es Bachiller en Economía de la Universidad del Pacífico del Perú. Correo electrónico: norallyfrk@gmail.com.

Javier Torres Gómez es Profesor del Departamento Académico de Economía de la Universidad del Pacífico del Perú. Correo electrónico: j.torresgomez@up.edu.pe. 



\section{Introducción}

La creciente participación de los sectores extractivos en la economía del Perú, que pasaron de representar el 9,3\% del producto interno bruto (PIB) en 2004 al 13,2\% en 2012, ha dado lugar a un notable aumento de los recursos fiscales que reciben las diferentes entidades gubernamentales por concepto de canon (minero, hidroenergético, gasífero y otros) ${ }^{1}$. Las transferencias en concepto de canon otorgadas a los gobiernos regionales y locales (municipalidades) representaron el $23 \%$ del total de transferencias en 2004, y ese porcentaje aumentó hasta el 43\% en $2012^{2}$.

El canon minero está constituido por el 50\% del impuesto sobre la renta que obtiene el Estado de los pagos de la actividad minera por el aprovechamiento de los recursos minerales, metálicos y no metálicos. Los recursos fiscales obtenidos por este concepto se distribuyen de la siguiente manera: el $10 \%$ del total del canon se asigna a los gobiernos locales de la municipalidad o las municipalidades distritales donde se explota el recurso natural; el 25\% se asigna a los gobiernos locales de las municipalidades distritales y provinciales donde se explota el recurso natural; el $40 \%$ se asigna a los gobiernos locales del departamento o los departamentos donde se explota el recurso natural; el 25\% se asigna a los gobiernos regionales donde se explota el recurso natural y, de ese porcentaje, los gobiernos regionales deben transferir un 20\% a las universidades nacionales de su jurisdicción.

De las entidades mencionadas, los principales beneficiados han sido los gobiernos locales, ya que recibieron por concepto de canon alrededor de 6.500 millones de nuevos soles para ejecutar proyectos de inversión pública en 2012. Esos recursos se pueden utilizar para financiar y cofinanciar proyectos de inversión pública que incluyan intervenciones orientadas a prestar servicios públicos y mantener la infraestructura, los dispensarios médicos y los hospitales, entre otras cosas. Los gobiernos regionales y locales pueden destinar hasta un $20 \%$ de esas transferencias al gasto corriente, es decir, al mantenimiento de los proyectos de inversión pública.

En consecuencia, de 2002 a 2011, el gasto total de las municipalidades distritales se multiplicó por 3,9 (véase el anexo A1). El componente que más aumentó fue el gasto de capital, que en 2011 se había multiplicado por 7,3 en comparación con 2002. Dicho crecimiento fue especialmente pronunciado en 2006 y 2008 , en los que el gasto de capital se incrementó en un $77 \%$ y un $70 \%$, respectivamente. El aumento del gasto de capital fue mayor en aquellas municipalidades que recibieron un volumen de canon más elevado. El gasto del $20 \%$ de las municipalidades que recibieron más canon creció en mayor medida que el gasto promedio de las demás municipalidades en la mayoría de los años del período 2002-2011, particularmente en 2006 (109\%) y 2008 (78\%).

En este contexto, es importante analizar la incidencia del factor político en el nivel del gasto de capital de las municipalidades distritales y el momento de ejecución de dicho gasto. Por ejemplo, en un informe de la Contraloría General de la República (2011) se señalaba que las transferencias efectuadas a algunos gobiernos locales no se habían traducido en mejoras en la cobertura de los servicios y la atención de las necesidades básicas de la población. En dicho informe se mencionaba

1 El canon es la participación de la que gozan los gobiernos regionales y locales en cuyas circunscripciones se explotan los recursos naturales, así como las universidades y los institutos superiores públicos, de los ingresos y las rentas obtenidos por el Estado en dicha actividad. Existen los siguientes cánones: minero, hidroenergético, gasífero, pesquero y forestal, así como el canon y el sobrecanon petrolero.

2 También hay otras transferencias hacia los gobiernos regionales y locales (provincias y distritos), en virtud del Fondo de Compensación Municipal (FONCOMUN), el Fondo de Desarrollo Socioeconómico de Camisea (FOCAM), los fideicomisos regionales, el Programa del Vaso de Leche, las donaciones y las regalías, entre otras. 
como una posible causa de ello la falta de orientación de los intereses políticos de las autoridades hacia el bienestar a largo plazo de sus localidades ${ }^{3,4}$.

Cabe mencionar que la capacidad de los gobiernos locales para administrar eficazmente la inversión pública es otro problema que está presente en la gestión pública peruana. Esa capacidad está limitada no solo por un sistema disfuncional de planificación y asignación presupuestaria, las trabas y restricciones en la ejecución de las actividades y la escasa articulación entre las instituciones y los programas públicos; las limitaciones en materia de capacidad técnica también influyen en este problema. Aragón y Casas (2009) hallaron evidencias de que la falta de capacidad relacionada con la gestión de la inversión, esto es, con la gestión de los proyectos, la contabilidad y las finanzas, el planeamiento y la coordinación con otras entidades públicas, puede afectar negativamente a la capacidad de los gobiernos locales para incrementar la inversión pública, aunque dispongan de recursos financieros (Aragón y Casas, 2009) 5 .

En el presente estudio se pretende determinar si el acceso a mayores transferencias por concepto de canon minero genera un incentivo adicional para una ejecución oportunista del gasto por parte de los alcaldes distritales. Los distritos que cuenten con un mayor volumen de transferencias tendrían más posibilidades de aumentar el monto del gasto de capital en el año previo a la celebración de elecciones.

El estudio centra la atención en el canon minero por tres motivos. En primer lugar, por la importancia de las transferencias por canon minero en el Perú. Dicho canon representó el $61 \%$ de las transferencias en virtud de algún tipo de canon en el período 2004-2012, con una tendencia creciente en la última década6.

En segundo lugar, por la naturaleza exógena del canon, ya que el monto de los recursos transferidos a cada gobierno subnacional está determinado por reglas establecidas previamente y depende en última instancia de los precios de los metales. Ello implica que las autoridades locales no tienen una influencia directa en la asignación de esos recursos. En estudios anteriores se ha utilizado el efecto exógeno del incremento del canon para evaluar las repercusiones de la minería en diferentes sectores de la economía del Perú. Aragón y Rud (2013), utilizando el caso de una mina de gran escala en una región del Perú (Cajamarca), determinaron la existencia de efectos positivos de la minería en las condiciones de vida de la población local, siendo la principal explicación el encadenamiento hacia atrás. Gajate-Garrido (2013) analizó el efecto del gasto público en la situación nutricional de los niños en el Perú. Partiendo del carácter endógeno del gasto público, utilizó como instrumento el canon minero regional no anticipado. Los resultados indicaban que el efecto positivo en la nutrición solo afecta a los niños de las zonas urbanas.

En tercer lugar, porque las transferencias por canon minero no revierten al tesoro público. Esta característica es muy importante, ya que ello podría crear incentivos para que la ejecución de los recursos se realice en el período que resulte más conveniente.

La investigación se centra en las municipalidades distritales porque reciben una proporción significativa de las transferencias por canon minero (véase el anexo A2). Además, los distritos son

3 En el informe también se indica que algunas municipalidades utilizaron los recursos públicos de forma inapropiada o realizaron pagos indebidos. Por ese motivo, en julio de 2012, la Contraloría General anunció la puesta en marcha del "Operativo Canon", cuyo propósito era determinar si los fondos obtenidos por los gobiernos locales y regionales por la explotación de los recursos naturales se habían utilizados de manera legal y eficaz.

4 Otras posibles causas son: i) un establecimiento inadecuado de las prioridades de los proyectos que se deben ejecutar en el marco de las normas que regulan la utilización del canon; ii) la falta de una planificación estratégica que permita evaluar las necesidades básicas insatisfechas de sus localidades, por ejemplo, en materia de agua y saneamiento, salud o educación; y iii) la limitada capacidad de gestión pública de los gobiernos regionales y locales.

5 No obstante, ese efecto no se aborda en este estudio.

6 Aunque la crisis financiera de 2008 redujo las utilidades netas de las empresas mineras, dichas transferencias se recuperaron a partir de 2010, alcanzando los 5.000 millones de nuevos soles en 2012. 
las unidades administrativas más pequeñas del Estado y sus acciones inciden directamente en la población. Por último, el control y la fiscalización a nivel distrital pueden resultar complejos, lo que otorgaría a los alcaldes cierta discrecionalidad para utilizar los recursos.

El resto del documento se organiza de la siguiente manera: en la sección Il se examina la literatura relacionada con el ciclo político presupuestal y la abundancia de recursos naturales. En las secciones III y IV se presentan las fuentes de información utilizadas y la metodología. En la sección $\mathrm{V}$ se analizan los resultados obtenidos. Por último, en la sección VI, se exponen las principales conclusiones.

\section{Examen de la literatura}

En esta sección se relaciona la literatura sobre la abundancia de recursos naturales con la relativa al ciclo político presupuestal.

\section{Abundancia de recursos}

El efecto de la abundancia de recursos fue tratado inicialmente por Gelb y otros (1988) y Auty (1990), quienes analizaron empíricamente la relación entre la explotación de los recursos naturales (el petróleo, en particular) y el crecimiento económico. Sin embargo, fue a partir del trabajo de Sachs y Warner (1995, 1997 y 2001) cuando se reconoció la solidez de la relación negativa y se acuñó la expresión "la maldición de los recursos". Según Sachs y Warner (2011), los países con abundantes recursos naturales suelen tener niveles de precios altos, lo que afecta directamente a la competitividad de otros sectores exportadores y, en consecuencia, dichos países pierden la posibilidad de lograr un crecimiento impulsado por las exportaciones.

Por otra parte, existe una vasta literatura en la que se demuestra que el efecto negativo de la abundancia de recursos naturales puede ser explicado por otros factores, como el nivel del capital humano o la calidad institucional pública. Por ejemplo, Gylfason (2001) demostró que el efecto negativo proviene de una menor preocupación en la educación por parte de las autoridades de los países ricos en recursos, lo que implica un nivel de gasto menor. En cuanto a la gestión pública, Manzano y Rigobon (2001) indicaron que el sobreendeudamiento de los países ricos en recursos naturales es el verdadero problema para el crecimiento. Asimismo, Hausmann y Rigobon (2002) analizaron la estructura del comercio y demostraron que las economías más diversificadas son menos propensas a sufrir efectos negativos debido a los recursos naturales.

Así, los países que consideran que el capital natural es su mayor activo pueden desarrollar un falso sentido de seguridad y llegar a ser negligentes en cuanto a la gestión de esos recursos y la acumulación de capital humano. Controlando esos efectos por medio de variables indirectas y utilizando otros métodos de medición para la abundancia de recursos naturales, Brunnschweiler (2008) halló una relación positiva directa entre los recursos naturales y el crecimiento económico en el período 1970-2000. Además, no encontró resultados significativos que confirmaran los efectos negativos entre la abundancia de recursos y la calidad institucional. De forma análoga, según Bravo-Ortega y De Gregorio (2005), cuando los niveles educativos son más elevados los efectos negativos se contrarrestan. Así, en promedio, los países con un alto capital humano obtendrían beneficios de los recursos naturales. En su estimación, los autores encontraron una relación positiva entre el nivel de ingresos y los recursos naturales. Como se puede observar, las explicaciones sobre el escaso desarrollo de los países con abundantes recursos naturales provienen sobre todo de la ciencia política y la economía. Según Isham y otros (2005), desde la perspectiva de la ciencia política, los dos principales efectos propuestos son el efecto renta y el efecto antimodernización. El primero ocurre cuando el 
aumento del presupuesto basado en los ingresos por la explotación de los recursos naturales permite que el gobierno tenga una mayor discrecionalidad, disminuyendo el control por parte de la población. Ese escaso control permite que el gasto del gobierno se utilice para fines distintos al de satisfacer las necesidades de la población o al de mejorar el nivel de productividad de la economía. Por ejemplo, Robinson, Torvik y Verdier (2005) señalaron que los períodos de auge de los recursos naturales, al elevar el valor de detentar el poder y proporcionar a los políticos mayores ingresos fiscales que pueden utilizar para influenciar el resultado de las elecciones, aumentan la mala asignación de los recursos en el resto de la economía. Collier y Goderis (2007) afirmaron que las rentas provenientes de los recursos naturales estimulan el cabildeo no productivo y la búsqueda de rentas, además de incentivar una distribución ineficiente en favor del apoyo político. Por otra parte, está la reducción de los incentivos a la modernización, tanto para el gobierno como para los trabajadores, debido a que el financiamiento del presupuesto (y, por ende, del gasto) proviene de una actividad extractiva específica que requiere habilidades especializadas. En consecuencia, la mayoría de la población queda excluida de la actividad relacionada con el recurso (aunque mantiene un beneficio pasivo), lo que reduce los incentivos para aumentar la productividad del resto de sectores y de los trabajadores en general.

En economía, se utiliza la expresión de la "enfermedad holandesa" para explicar el resultado aparentemente contradictorio de tener más recursos y un crecimiento menor. La explotación de los recursos naturales altera los precios relativos de los demás bienes y servicios, lo que genera una reasignación interna del capital y el trabajo de los sectores comercializables hacia las actividades extractivas, así como un crecimiento de los sectores no comercializables (servicios) ${ }^{7}$. La especialización de la economía es eficiente a corto plazo, pero, al disminuir el nivel de explotación del recurso (o agotarse por completo), la economía carece de otros sectores lo suficientemente desarrollados como para mantener el nivel de producción anterior o absorber la nueva mano de obra que busca empleo.

Collier (2010) observó, sin embargo, que, aunque la explicación inicial fue puramente económica, cada vez es más evidente la importancia de los factores políticos. Asimismo, Deacon (2011) indicó que algunos patrones empíricos habían dado lugar al examen de las interacciones con las instituciones políticas. Específicamente, señaló que es más probable que la abundancia de recursos resulte una maldición cuando: i) la gobernanza y el estado de derecho sean inicialmente débiles; y ii) la disposición del recurso se encuentre altamente concentrada.

\section{Ciclo político presupuestal}

El ciclo político presupuestal se define como una fluctuación periódica de la política fiscal del gobierno inducida por la ciclicidad de las elecciones (véase más información en Shi y Svensson (2001)). El comportamiento oportunista de los gobernantes se manifiesta en una gestión de la política fiscal (impuestos, transferencias y gasto público) destinada a influir en las preferencias de los votantes y a aumentar sus probabilidades de triunfo electoral (Gámez e Ibarra-Yúnez, 2007).

La literatura sobre el ciclo político presupuestal se puede dividir en dos grupos. Uno de ellos sigue el modelo teórico desarrollado por Rogoff (1990), que se centra en la cuestión de la información asimétrica sobre el nivel de competencia de los políticos. Los votantes forjan sus expectativas de voto sobre la base de los resultados observables de la política fiscal en ese período. El supuesto fundamental es que solo los alcaldes más competentes pueden incrementar el gasto (o el gasto observable) en un

\footnotetext{
7 Isham y otros (2005) también mencionan el efecto de la inequidad arraigada. Esta hace referencia a las distintas trayectorias de desarrollo en las antiguas colonias (determinadas por el calendario y la naturaleza de la descolonización, los regímenes de derechos de propiedad y el tipo de producción que tenían), que permiten explicar los efectos de los recursos naturales en sus economías en la actualidad.
} 
determinado período. En el año anterior a las elecciones, esas autoridades aumentan el gasto para enviar una señal de competencia al electorado, con el fin de que este las favorezca en las elecciones ${ }^{8}$. Así pues, la señalización da lugar a los ciclos políticos presupuestales.

Por otra parte, los modelos del segundo grupo se centran en la habilidad de los alcaldes para gestionar la política fiscal con el fin de sesgar las preferencias de los votantes (Shi y Svensson, 2001). Si una mayor provisión de bienes públicos (o el mayor gasto de capital) puede ser entendida por la población como una señal de que se tiene un mayor nivel de competencia, todos los políticos tendrían los mismos incentivos para incrementar el gasto en los períodos previos a las elecciones. A diferencia del modelo de Rogoff, en estos modelos se plantea que, independientemente de su nivel de competencia, todos los políticos tienen la misma capacidad de incrementar el gasto público.

Al margen del distinto énfasis de los modelos en las señales sobre el nivel de competencia o en la capacidad del gasto para influir en las preferencias de los votantes, la principal conclusión es que el gasto público está afectado por el calendario electoral ${ }^{9}$.

En un primer momento, los estudios empíricos se centraron en probar la existencia del ciclo político presupuestal a nivel de los países. Por ejemplo, Shi y Svensson (2006) examinaron la presencia de dicho ciclo en una muestra de países en desarrollo y desarrollados. Los autores hallaron que dicho ciclo existía en los dos tipos de países, aunque en mayor grado en los primeros.

Recientemente, se ha utilizado la mayor información disponible a nivel subnacional para probar la existencia del ciclo político presupuestal a nivel local. Akhmedov, Ravichev y Zhuravskaya (2002) encontraron evidencias de ciclos políticos cortos en las regiones de Rusia en el período 1996-2001. Drazen y Eslava (2005 y 2008) estudiaron el ciclo político presupuestal en las municipalidades colombianas y hallaron evidencias de que este influye en el cambio de la composición del gasto en el período preelectoral. Del mismo modo, Gámez e lbarra-Yúnez (2007) evidenciaron la existencia de dicho ciclo en el gasto público a nivel estatal en México.

En cuanto al efecto de los beneficios de las industrias extractivas en las elecciones, Monteiro (2009) y Monteiro y Ferraz (2012) evaluaron la repercusión de las regalías por petróleo que reciben las municipalidades en el Brasil y concluyeron que las regalías generan ventajas para los gobernantes en funciones y reducen la competencia política, aunque el efecto desaparece a medio plazo.

En el Perú, Carranza, Chávez y Valderrama (2006) estudiaron la economía política del proceso presupuestario a nivel nacional y demostraron la existencia de ciclos políticos presupuestales en el gasto público no financiero durante la administración de Fujimori (1995-2000). Sin embargo, a nivel subnacional, no se ha evaluado la existencia del ciclo político presupuestal ni el efecto de las rentas de los recursos extractivos en el comportamiento fiscal de las autoridades. El estudio más cercano es el de Sanguinetti (2010), que analizó el efecto del canon en las prácticas fiscales a nivel regional. Dicho autor halló que las transferencias por canon alteran la composición del gasto e incrementan la importancia relativa de la inversión pública. Este resultado, no obstante, sería una consecuencia de las restricciones en el uso de los recursos provenientes del canon.

El presente estudio es uno de los pocos en los que se analiza la ciclicidad de la ejecución del gasto público peruano a nivel distrital y su relación con las transferencias recibidas como producto de la explotación de los recursos mineros.

\footnotetext{
8 Se califica de "competente" al alcalde que necesita menos ingresos para proveer un nivel determinado de servicios públicos.

9 Cabe señalar que la gestión preelectoral no solo se puede entender como el incremento del gasto o la generación de déficits. Drazen y Eslava (2005) proponen que se presenta en forma de cambios en la composición del gasto, destinando una mayor cantidad de recursos hacia los votantes más influenciables por las variaciones de la política fiscal o hacia aquellos gastos más valorados por la mayoría de los votantes.
} 


\section{Fuentes de información}

La primera parte del análisis se basa en un panel balanceado de datos de 1.131 municipalidades distritales, correspondientes al período 2002-2011 ${ }^{10}$. La base contiene información presupuestaria, como el gasto de capital ejecutado, los recursos recibidos por concepto de canon minero y el presupuesto general de cada distrito ${ }^{11}$. La información proviene del Portal de Transparencia Económica del Ministerio de Economía y Finanzas, y se utiliza tanto en millones de nuevos soles como en términos per cápita. Cabe señalar que, para identificar adecuadamente el efecto del canon, se decidió restar el monto presupuestado de canon minero del presupuesto de cada distrito. De esta manera, el presupuesto general refleja mejor la disponibilidad de recursos del distrito. Por último, dado que para evaluar los ciclos políticos presupuestarios hace falta valorar, al menos, cuatro años (período del mandato en el Perú), es evidente que la base de datos hace referencia a dos ciclos políticos (2002-2006, 2006-2010 y 2011).

Además de la información presupuestal, se incorporaron variables de control (demográficas, laborales y de ingresos) que podrían incidir en el nivel del gasto de capital. Así, se ha incluido la población proyectada por distrito, la proporción de población económicamente activa por distrito, la tasa de analfabetismo departamental, la proporción de población rural a nivel de departamento, la ratio de dependencia a nivel provincial y el nivel pobreza por departamento. Estos datos provienen de los cálculos y las estimaciones realizados por el Instituto Nacional de Estadística e Informática (INEI).

\section{Metodología}

Para comprobar la existencia de un ciclo político presupuestal y evaluar el efecto del canon sobre este, se analizan: el gasto de capital como una función de variables económicas y demográficas, un conjunto de variables ficticias por año y el monto transferido por concepto de canon minero. En particular, se plantean los siguientes modelos:

$$
\begin{gathered}
G_{i, t}=\alpha_{i}+X_{i, t \square}^{\prime} \beta+\sum_{2002}^{2011} \gamma_{t} D_{t}+\delta_{1} \text { canon }_{i, t}+\sum_{t=06,10}^{\square} D_{t} \delta_{2 t} \text { canon }_{i, t \square}+\varepsilon_{i t} \\
G_{i, t}=\alpha_{i}+X_{i, t}^{\prime} \beta+\sum_{2002}^{2011} \gamma_{t} D_{t}+\delta_{1} \text { canon }_{i, t}+\sum_{t=06,10}^{\square}\left(\sum_{g=1}^{g=5} \delta_{2 g t} D_{t} D_{g}\right)+\varepsilon_{i t}
\end{gathered}
$$

$G_{i, t}$ es el gasto de capital per cápita ejecutado por el distrito $i$ en el año $t$. La variable $X_{i, t}$ agrupa los controles sociodemográficos y económicos (por ejemplo, el presupuesto municipal per cápita al principio del período, la tasa de analfabetismo y la proporción de población rural). La sumatoria de las variables dicotómicas por año $\left(D_{t}\right)$ muestra el ciclo político del gasto.

Dado que un alcalde reelecto tiene más experiencia en la gestión y la ejecución del gasto que uno que haya sido elegido por primera vez, se incluye un control del número de años en el cargo (reelec).

El efecto del canon minero se identifica con dos variables. La variable cannon $_{i, t}$ recoge el efecto directo del monto de la transferencia (per cápita) sobre el gasto, mientras que la interacción de las variables ficticias en los años electorales y el monto del canon $\left(D_{t} \delta_{2 t}\right.$ cannon $\left._{i, t}\right)$ identificaría el efecto incremental en el gasto de las elecciones.

\footnotetext{
${ }^{10}$ El universo de municipalidades distritales peruanas en 2011 era de 1.635. Sin embargo, en este estudio solo se consideran aquellas de las que se dispone de observaciones anuales para todo el período analizado.

${ }^{11}$ En la variable "presupuesto" se utiliza el presupuesto inicial modificado (PIM), porque es el que efectivamente reciben las municipalidades.
} 
Se plantean dos especificaciones. La primera (1) incorpora el efecto del monto del canon de manera lineal, mientras que la segunda (2) separa los distritos en cinco grupos $(g)$, según el monto de canon que reciben, tratando de recoger posibles efectos discontinuos. Ambas estimaciones utilizan efectos fijos por distritos y errores estándar robustos. Así, la identificación del efecto del canon provendría de los cambios entre las municipalidades distritales a lo largo del tiempo.

\section{Estimación empírica}

\section{Ciclo político presupuestal}

En el cuadro 1 se presentan los resultados básicos del modelo en términos per cápita ${ }^{12}$. El efecto del presupuesto (sin considerar las transferencias por canon) es significativo y positivo. Más recursos generarían una mayor capacidad de gasto. Además, la variable del canon minero tiene un efecto positivo y significativo en el gasto de capital. Es decir, las municipalidades que tienen más recursos disponibles debido al canon minero suelen ejecutar un mayor gasto de capital.

Las variables ficticias que recogen el efecto por año resultan significativas estadísticamente, por lo que se puede afirmar que el gasto de capital está influenciado por el período de ejecución. Además, se observa que los coeficientes de 2006 y 2010 son superiores a los de 2005 y 2009 en todas las especificaciones. Sin embargo, cabe señalar que no se observa un ciclo político completamente marcado, ya que los coeficientes estimados para los años posteriores a las elecciones (2007 y 2011) son positivos y mayores que los coeficientes estimados para los años electorales.

Aunque en diversos estudios se indica que el ciclo político presupuestal debería observarse en los años preelectorales (2005 y 2009), las elecciones municipales peruanas tuvieron lugar el tercer domingo de noviembre del año en el que finalizó el mandato de las autoridades municipales. Ello quiere decir que el año pertinente para analizar el gasto público es aquel en el que se celebraron las elecciones (2006 y 2010). Las autoridades en ejercicio dispusieron prácticamente de un año completo para ejecutar gastos que podrían influir en las preferencias de los votantes ${ }^{13}$.

Cuadro 1

Ciclo político presupuestal

(En millones de nuevos soles)

\begin{tabular}{|c|c|c|c|c|}
\hline & (1) & (2) & (3) & (4) \\
\hline \multirow[t]{2}{*}{ Población analfabeta } & & & & $-0,00124$ \\
\hline & & & & $(0,000283)^{\star \star \star}$ \\
\hline \multirow[t]{2}{*}{ Población rural } & & & & 0,000378 \\
\hline & & & & $(0,000792)$ \\
\hline \multirow[t]{2}{*}{ Emergencias } & & & & $2,13 e-08$ \\
\hline & & & & $(2,05 e-07)$ \\
\hline \multirow[t]{2}{*}{ Reelección } & & & & $-2,17 e-06$ \\
\hline & & & & $(6,89 e-06)$ \\
\hline \multirow[t]{2}{*}{ Ingreso (per cápita) } & 0,154 & & 0,130 & 0,129 \\
\hline & $(0,0309)^{\star \star \star}$ & & $(0,0286)^{\star \star *}$ & $(0,0287)^{\star \star \star}$ \\
\hline \multirow[t]{2}{*}{ Canon minero (per cápita) } & 0,171 & & 0,170 & 0,170 \\
\hline & $(0,0423)^{\star \star \star}$ & & $(0,0382)^{\star \star *}$ & $(0,0382)^{\star \star \star}$ \\
\hline
\end{tabular}

\footnotetext{
12 En el modelo en niveles estimado (que incorpora el tamaño de la población distrital) no hay diferencias importantes.

${ }^{13}$ A pesar de la existencia de reglas fiscales que limitan el incremento del gasto en los años electorales, su falta de operatividad hace que no actúen como un factor limitante del gasto.
} 
Cuadro 1 (conclusión)

\begin{tabular}{|c|c|c|c|c|}
\hline & (1) & (2) & (3) & (4) \\
\hline \multirow[t]{2}{*}{2003} & & 1,81e-05 & $1,13 e-05$ & $4,12 \mathrm{e}-06$ \\
\hline & & $(3,32 \mathrm{e}-06)^{\star \star \star}$ & $(2,98 \mathrm{e}-06)^{\star \star \star}$ & $(1,77 e-05)$ \\
\hline \multirow[t]{2}{*}{2004} & & $6,97 e-05$ & 4,66e-05 & $3,55 e-05$ \\
\hline & & $(3,95 e-06)^{\star \star \star}$ & $(6,04 \mathrm{e}-06)^{\star \star \star}$ & $(1,42 \mathrm{e}-05)^{\star *}$ \\
\hline \multirow[t]{2}{*}{2005} & & $5,24 \mathrm{e}-05$ & $2,78 \mathrm{e}-05$ & $1,69 e-05$ \\
\hline & & $(6,83 e-06)^{\star \star \star}$ & $(6,97 e-06)^{\star \star \star}$ & $(2,02 e-05)$ \\
\hline \multirow[t]{2}{*}{2006} & & 0,000213 & 0,000167 & 0,000155 \\
\hline & & $(1,52 \mathrm{e}-05)^{\star \star \star}$ & $(1,45 e-05)^{\star \star \star}$ & $(3,51 \mathrm{e}-05)^{\star \star \star}$ \\
\hline \multirow[t]{2}{*}{2007} & & 0,000300 & 0,000203 & 0,000170 \\
\hline & & $(1,90 \mathrm{e}-05)^{\star \star \star}$ & $(1,55 e-05)^{\star \star \star}$ & $(3,26 e-05)^{\star \star \star}$ \\
\hline \multirow[t]{2}{*}{2008} & & 0,000507 & 0,000375 & 0,000341 \\
\hline & & $(2,88 \mathrm{e}-05)^{\star \star \star}$ & $(2,40 \mathrm{e}-05)^{\star \star \star}$ & $(4,69 e-05)^{\star \star \star}$ \\
\hline \multirow[t]{2}{*}{2009} & & 0,000504 & 0,000296 & 0,000258 \\
\hline & & $(2,19 \mathrm{e}-05)^{\star \star \star}$ & $(2,30 \mathrm{e}-05)^{\star \star \star}$ & $(4,54 \mathrm{e}-05)^{\star \star \star}$ \\
\hline \multirow[t]{2}{*}{2010} & & 0,000590 & 0,000396 & 0,000361 \\
\hline & & $(3,90 e-05)^{\star \star \star}$ & $(3,78 \mathrm{e}-05)^{\star \star \star}$ & $(8,12 \mathrm{e}-05)^{\star \star \star}$ \\
\hline \multirow[t]{2}{*}{2011} & & 0,000628 & 0,000437 & 0,000393 \\
\hline & & $(3,41 \mathrm{e}-05)^{\star \star \star}$ & $(3,78 \mathrm{e}-05)^{\star \star \star}$ & $(7,38 \mathrm{e}-05)^{\star * \star}$ \\
\hline \multirow[t]{2}{*}{ Constante } & 0,000270 & 0,000125 & $9,17 e-05$ & 0,000113 \\
\hline & $(2,08 \mathrm{e}-05)^{\star \star \star}$ & $(1,43 e-05)^{\star \star \star}$ & $(9,30 \mathrm{e}-06)^{\star \star \star}$ & $(0,000334)$ \\
\hline Observaciones & 11,310 & 11,310 & 11,310 & 11,310 \\
\hline R-cuadrado & 0,377 & 0,161 & 0,448 & 0,449 \\
\hline
\end{tabular}

Fuente: Elaboración propia.

Nota: Los errores estándar robustos figuran entre paréntesis. * denota significancia al $10 \%$, ${ }^{*}$ significancia al $5 \%$ y ${ }^{\star \star *}$ significancia al $1 \%$.

En el gráfico 1 se observa la evolución del gasto estimado, utilizando los coeficientes de la columna 4 y el promedio de las variables de control, dejando que la variación en la evolución del gasto provenga exclusivamente del efecto por año. Dicha evolución muestra que, en 2006 y 2010, el gasto de capital aumentó un 37,1\% en promedio en comparación con los años anteriores (2005 y 2009, respectivamente). El incremento de 2006 fue significativamente mayor que el de $2010^{14}$. No obstante, también hubo un aumento del gasto de capital posterior, en 2007 y 2011, de aproximadamente un $4,6 \%$.

Con respecto a las variables de control, se observa que una mayor proporción de población analfabeta está asociada significativamente a un menor nivel de gasto de capital. La proporción de población analfabeta podría interpretarse como una aproximación de la capacidad de gestión local, que, al ser menor, se reflejaría también en una menor ejecución de gasto. Por otra parte, la participación laboral (porcentaje de la población que pertenece a la población económicamente activa) presenta un coeficiente positivo y significativo. La relación entre el gasto de capital y la proporción de personas que vive en zonas rurales es negativa, aunque no significativa ${ }^{15}$. De forma análoga, ni el número de desastres naturales ni el número de años en el cargo parecen tener efectos importantes en el gasto.

\footnotetext{
14 También se observa un incremento significativo en 2008.

${ }^{15}$ La variable "pobreza" tiene una elevada correlación con la población rural, por lo que no se ha incluido. Además, solo se dispone de datos a nivel distrital hasta 2010.
} 


\section{Gráfico 1}

Predicción de la desviación del gasto de capital per cápita con respecto a 2002

(En millones de nuevos soles)

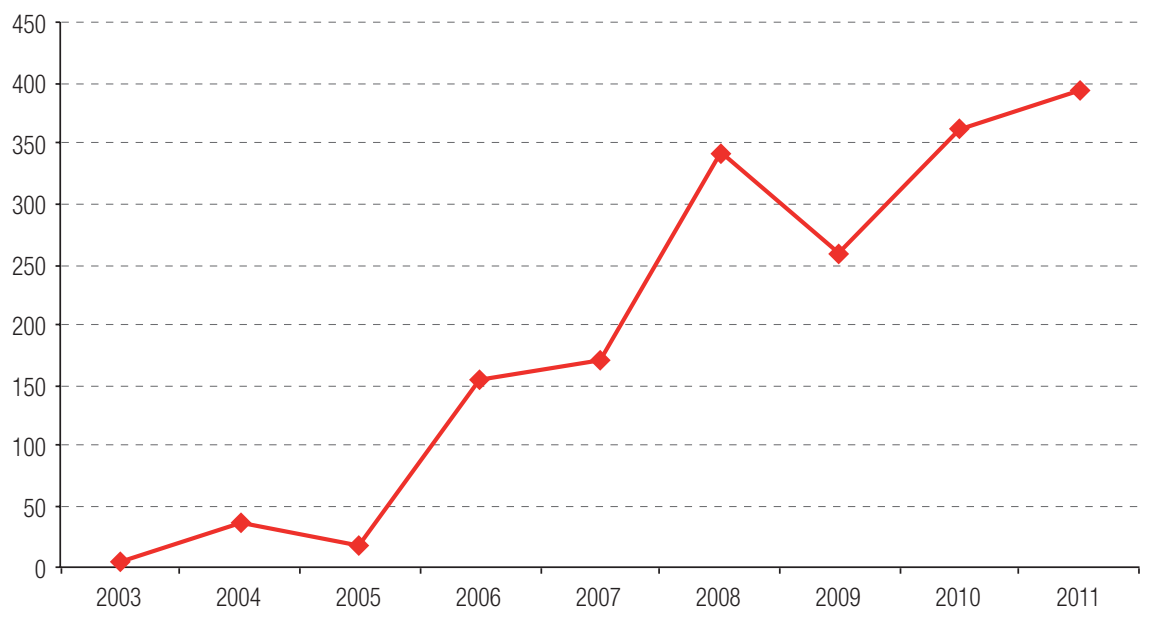

Fuente: Elaboración propia, sobre la base de datos del Ministerio de Economía y Finanzas (MEF).

\section{Efecto del canon en el ciclo político presupuestal}

Para determinar si, en los años electorales, el acceso al canon minero da lugar a un mayor gasto de capital, se añadieron variables ficticias multiplicativas al modelo anterior. Es decir, se multiplicaron las variables ficticias anuales por el monto de canon recibido en dicho período. De esta manera, el análisis se centra en el efecto incremental del canon minero en los años electorales.

Los resultados se presentan en el cuadro 2. La primera columna muestra que los coeficientes de las variables ficticias multiplicativas anuales en los años previos a las elecciones (2005 y 2009) no son significativos. A partir de la segunda columna, el análisis se centra en los años electorales. En la segunda especificación, el coeficiente de la variable ficticia multiplicativa para ambos años resulta significativo y positivo ${ }^{16}$, lo que indicaría que el canon minero tiene un efecto incremental en el gasto de capital en los años electorales. La tercera especificación considera, además, los años previo y posterior al período electoral, con la finalidad de comprobar la solidez de los resultados. El efecto solo es significativo para 2006 y pierde toda significancia para 2010.

En las columnas cuarta y quinta se elimina el efecto directo del canon minero y se lo incorpora por medio de las interacciones con las variables ficticias anuales. La cuarta columna incluye variables ficticias anuales alrededor de las elecciones y la quinta columna añade variables ficticias para todos los años. Se observa que el efecto incremental del canon es positivo y, en este caso, significativo en ambos años electorales. Sin embargo, el coeficiente de la interacción de 2011 es aún mayor que el de 2010, aunque no es significativo.

${ }^{16}$ Aunque para 2010 solo es significativo con una confianza del 90\%. 


\section{Cuadro 2}

Ciclo político presupuestal

(En millones de nuevos soles)

\begin{tabular}{|c|c|c|c|c|c|}
\hline & (1) & (2) & (3) & (4) & (5) \\
\hline \multirow[t]{2}{*}{ Población analfabeta } & $-0,00116$ & $-0,00116$ & $-0,00116$ & $-0,00108$ & $-0,00110$ \\
\hline & $(0,000286)^{\star \star \star}$ & $(0,000286)^{\star \star \star}$ & $(0,000276)^{\star \star \star}$ & $(0,000260)^{\star \star \star}$ & $(0,000259)^{\star \star \star}$ \\
\hline \multirow[t]{2}{*}{ Población rural } & $7,32 \mathrm{e}-05$ & 0,000359 & $2,15 e-05$ & 0,000283 & 0,000232 \\
\hline & $(0,000694)$ & $(0,000792)$ & $(0,000656)$ & $(0,000671)$ & $(0,000658)$ \\
\hline \multirow[t]{2}{*}{ Emergencias } & $9,20 \mathrm{e}-08$ & $5,81 e-08$ & $1,41 e-07$ & $9,32 \mathrm{e}-08$ & $8,07 e-08$ \\
\hline & $(1,89 e-07)$ & $(2,01 e-07)$ & $(1,82 \mathrm{e}-07)$ & $(1,80 \mathrm{e}-07)$ & $(1,77 \mathrm{e}-07)$ \\
\hline \multirow[t]{2}{*}{ Reelección } & $-2,80 e-06$ & $-1,87 \mathrm{e}-06$ & $-1,18 \mathrm{e}-06$ & $2,98 \mathrm{e}-07$ & $-4,22 e-07$ \\
\hline & $(7,09 \mathrm{e}-06)$ & $(6,76 e-06)$ & $(5,97 e-06)$ & $(6,03 e-06)$ & $(6,25 e-06)$ \\
\hline \multirow[t]{2}{*}{ Ingreso (per cápita) } & 0,140 & 0,134 & 0,139 & 0,200 & 0,193 \\
\hline & $(0,0212)^{\star \star \star}$ & $(0,0282)^{\star * *}$ & $(0,0240)^{\star \star \star}$ & $(0,0302)^{\star \star *}$ & $(0,0303)^{\star \star \star}$ \\
\hline \multirow[t]{2}{*}{ Canon minero (per cápita) } & 0,206 & 0,145 & 0,182 & & \\
\hline & $(0,0488)^{\star \star \star}$ & $(0,0375)^{\star * \star}$ & $(0,0592)^{\star \star \star}$ & & \\
\hline \multirow[t]{2}{*}{2003} & $-9,23 e-07$ & $5,02 e-06$ & $3,62 \mathrm{e}-06$ & $1,04 \mathrm{e}-05$ & $6,03 e-07$ \\
\hline & $(1,87 e-05)$ & $(1,75 e-05)$ & $(1,67 e-05)$ & $(1,72 \mathrm{e}-05)$ & $(1,85 e-05)$ \\
\hline \multirow[t]{2}{*}{2004} & $2,70 e-05$ & $3,57 e-05$ & 2,92e-05 & $3,18 \mathrm{e}-05$ & $2,44 \mathrm{e}-05$ \\
\hline & $(1,25 e-05)^{\star \star}$ & $(1,46 \mathrm{e}-05)^{\star \star}$ & $(1,36 \mathrm{e}-05)^{\star \star}$ & $(1,53 e-05)^{\star \star}$ & $(1,94 \mathrm{e}-05)$ \\
\hline \multirow[t]{2}{*}{2005} & 5,61e-06 & $1,75 e-05$ & $3,04 \mathrm{e}-06$ & 6,32e-06 & $1,75 e-06$ \\
\hline & $(1,78 \mathrm{e}-05)$ & $(2,08 \mathrm{e}-05)$ & $(1,69 e-05)$ & $(1,86 e-05)$ & $(1,92 \mathrm{e}-05)$ \\
\hline \multirow[t]{2}{*}{2006} & 0,000140 & 0,000130 & 0,000115 & 0,000121 & 0,000115 \\
\hline & $(2,97 e-05)^{\star \star \star}$ & $(3,07 e-05)^{\star \star \star}$ & $(2,38 e-05)^{\star \star \star}$ & $(2,45 e-05)^{\star \star \star}$ & $(2,47 e-05)^{\star \star \star}$ \\
\hline \multirow[t]{2}{*}{2007} & 0,000143 & 0,000179 & 0,000156 & 0,000187 & 0,000178 \\
\hline & $(2,94 \mathrm{e}-05)^{\star \star \star}$ & $(3,60 \mathrm{e}-05)^{\star \star \star}$ & $(3,02 \mathrm{e}-05)^{\star \star \star}$ & $(3,13 e-05)^{\star \star \star}$ & $(3,33 e-05)^{\star \star \star}$ \\
\hline \multirow[t]{2}{*}{2008} & 0,000311 & 0,000349 & 0,000319 & 0,000360 & 0,000321 \\
\hline & $(3,86 e-05)^{\star \star \star}$ & $(5,01 e-05)^{\star \star \star}$ & $(4,31 e-05)^{\star \star \star}$ & $(4,59 e-05)^{\star \star \star}$ & $(4,29 e-05)^{\star \star \star}$ \\
\hline \multirow[t]{2}{*}{2009} & 0,000278 & 0,000267 & 0,000277 & 0,000288 & 0,000284 \\
\hline & $(5,49 e-05)^{\star \star \star}$ & $(4,95 \mathrm{e}-05)^{\star \star \star}$ & $(5,11 e-05)^{\star \star \star}$ & $(5,14 \mathrm{e}-05)^{\star \star \star}$ & $(4,96 \mathrm{e}-05)^{\star \star *}$ \\
\hline \multirow[t]{2}{*}{2010} & 0,000323 & 0,000334 & 0,000304 & 0,000305 & 0,000302 \\
\hline & $(6,69 e-05)^{\star \star \star}$ & $(7,08 \mathrm{e}-05)^{\star \star \star}$ & $(5,54 \mathrm{e}-05)^{\star \star \star}$ & $(6,18 \mathrm{e}-05)^{\star \star \star}$ & $(6,22 \mathrm{e}-05)^{\star \star \star}$ \\
\hline \multirow[t]{2}{*}{2011} & 0,000351 & 0,000400 & 0,000333 & 0,000341 & 0,000332 \\
\hline & $(5,72 \mathrm{e}-05)^{\star \star \star}$ & $(7,80 \mathrm{e}-05)^{\star \star \star}$ & $(4,13 e-05)^{\star \star \star}$ & $(4,52 \mathrm{e}-05)^{\star \star \star}$ & $(4,55 \mathrm{e}-05)^{\star \star \star}$ \\
\hline \multirow[t]{2}{*}{ Interacción: canon²003 } & & & & & 6,92e-05 \\
\hline & & & & & $(3,68 e-05)^{*}$ \\
\hline \multirow[t]{2}{*}{ Interacción: canon*2004 } & & & & & $4,45 e-05$ \\
\hline & & & & & $(5,55 e-05)$ \\
\hline \multirow[t]{2}{*}{ Interacción: canon*2005 } & $2,98 \mathrm{e}-06$ & & $1,44 \mathrm{e}-05$ & $3,23 e-05$ & 4,52e-05 \\
\hline & $(1,80 \mathrm{e}-05)$ & & $(1,58 \mathrm{e}-05)$ & $(1,63 e-05)^{\star *}$ & $(2,23 e-05)^{\star *}$ \\
\hline \multirow[t]{2}{*}{ Interacción: canon²006 } & & $4,48 \mathrm{e}-05$ & 4,24e-05 & $5,99 e-05$ & 6,96e-05 \\
\hline & & $(1,18 \mathrm{e}-05)^{\star \star \star}$ & $(1,46 \mathrm{e}-05)^{\star \star \star}$ & $(1,54 \mathrm{e}-05)^{\star \star \star}$ & $(1,91 \mathrm{e}-05)^{\star \star \star}$ \\
\hline \multirow[t]{2}{*}{ Interacción: canon*2007 } & & & $-1,67 e-06$ & 1,62e-05 & $2,00 e-05$ \\
\hline & & & $(6,83 e-06)$ & $(7,43 e-06)^{\star \star}$ & $(9,61 e-06)^{\star *}$ \\
\hline Interacción: canon*2008 & & & & & $2,17 e-05$ \\
\hline & & & & & $(1,25 e-05)^{\star}$ \\
\hline Interacción: canon*2009 & $-2,35 e-05$ & & $-1,95 e-05$ & $-1,08 \mathrm{e}-05$ & $-8,01 e-06$ \\
\hline & $(1,50 e-05)$ & & $(1,24 \mathrm{e}-05)$ & $(1,09 e-05)$ & $(9,11 e-06)$ \\
\hline Interacción: canon²010 & & $1,51 \mathrm{e}-05$ & 1,06e-05 & $2,03 e-05$ & 2,31e-05 \\
\hline & & $(8,85 e-06)^{\star}$ & $(8,67 e-06)$ & $(9,36 \mathrm{e}-06)^{\star *}$ & $(1,10 \mathrm{e}-05)^{\star *}$ \\
\hline Interacción: canon²011 & & & $1,36 \mathrm{e}-05$ & 2,31e-05 & $2,80 \mathrm{e}-05$ \\
\hline & & & $(1,70 \mathrm{e}-05)$ & $(1,99 e-05)$ & $(2,13 e-05)$ \\
\hline Constante & 0,000236 & 0,000108 & 0,000252 & 0,000105 & 0,000137 \\
\hline & $(0,000289)$ & $(0,000337)$ & $(0,000274)$ & $(0,000281)$ & $(0,000277)$ \\
\hline Observaciones & 11,310 & 11,310 & 11,310 & 11,310 & 11,310 \\
\hline R-cuadrado & 0,481 & 0,464 & 0,491 & 0,464 & 0,472 \\
\hline
\end{tabular}

Fuente: Elaboración propia.

Nota: Los errores estándar robustos figuran entre paréntesis. * denota significancia al $10 \%$, ${ }^{* *}$ significancia al $5 \%$ y *** significancia al $1 \%$. 
Se concluye así que la recepción de transferencias por canon minero tiene un efecto incremental en el gasto de capital en 2006. No obstante, ese efecto incremental es menos notorio en el ciclo electoral de 2010. Así pues, un incremento en las transferencias de canon minero per cápita da lugar a un menor aumento del gasto de capital per cápita en 2010, en comparación con 2006.

\section{Categorización de las municipalidades según el volumen de canon minero recibido}

Como aproximación alternativa (véase la ecuación (2), en la sección sobre la metodología), se clasificó a las municipalidades en quintiles según el monto de canon minero recibido en $2011^{17}$. Las transferencias por canon minero a las municipalidades pertenecientes al primer grupo son de entre 0 y 0,007 millones de nuevos soles; las del segundo grupo, de entre 0,007 y 0,098 millones de nuevos soles; las del tercer grupo, de entre 0,098 y 0,466 millones de nuevos soles; las del cuarto grupo, de entre 0,466 y 1,549 millones de nuevos soles; y las transferencias del quinto grupo son superiores a 1,549 millones de nuevos soles. Cada grupo está compuesto aproximadamente por 230 municipalidades.

Además, se crearon interacciones con las variables ficticias por año (desde 2005) para todos los grupos de municipalidades: 24 interacciones (6 variables binarias por año para los grupos 2, 3, 4 y 5). De esta manera, se evalúa si en las municipalidades que reciben mayores transferencias por canon minero se acentúa el gasto de capital. En el cuadro 3 se presentan los resultados.

En la primera especificación se consideran las interacciones de los años preelectorales (2005 y 2009) en todos los grupos. Los resultados son mixtos. En 2005, el efecto incremental es significativo para dos grupos de distritos y presenta un signo negativo. En 2009, el efecto incremental es significativo y positivo para todos los grupos, excepto para el último.

\section{Cuadro 3}

Ciclo político presupuestal con efecto incremental del canon (En millones de nuevos soles)

\begin{tabular}{|c|c|c|c|c|}
\hline & (1) & (2) & (3) & (4) \\
\hline \multirow[t]{2}{*}{ Población analfabeta } & $-0,00109$ & $-0,00116$ & $-0,00106$ & $-0,000959$ \\
\hline & $(0,000292)^{\star \star *}$ & $(0,000290)^{\star \star \star}$ & $(0,000294)^{\star \star *}$ & $(0,000267)^{\star \star \star}$ \\
\hline \multirow[t]{2}{*}{ Población rural } & 0,000157 & 0,000375 & 0,000237 & 0,000566 \\
\hline & $(0,000775)$ & $(0,000800)$ & $(0,000796)$ & $(0,000902)$ \\
\hline \multirow[t]{2}{*}{ Emergencias } & $1,84 \mathrm{e}-08$ & $6,63 e-08$ & $4,04 \mathrm{e}-08$ & $2,67 e-08$ \\
\hline & $(2,06 e-07)$ & $(1,94 \mathrm{e}-07)$ & $(1,75 e-07)$ & $(1,78 \mathrm{e}-07)$ \\
\hline \multirow[t]{2}{*}{ Reelección } & $-2,24 e-06$ & $-2,30 e-06$ & $-2,95 e-06$ & $-1,61 e-06$ \\
\hline & $(6,96 e-06)$ & $(6,84 \mathrm{e}-06)$ & $(6,89 e-06)$ & $(6,59 e-06)$ \\
\hline \multirow{2}{*}{ Ingreso (per cápita) } & 0,130 & 0,128 & 0,130 & 0,197 \\
\hline & $(0,0283)^{\star \star \star}$ & $(0,0289)^{\star * \star}$ & $(0,0289)^{\star \star \star *}$ & $(0,0276)^{\star \star \star}$ \\
\hline \multirow[t]{2}{*}{ Canon minero (per cápita) } & 0,171 & 0,169 & 0,167 & \\
\hline & $(0,0383)^{\star \star \star}$ & $(0,0378)^{\star \star \star}$ & $(0,0381)^{\star \star \star}$ & \\
\hline \multirow[t]{2}{*}{2003} & $2,73 e-06$ & $3,73 e-06$ & $1,17 \mathrm{e}-06$ & $7,41 \mathrm{e}-06$ \\
\hline & $(1,79 e-05)$ & $(1,75 e-05)$ & $(1,76 e-05)$ & $(1,68 e-05)$ \\
\hline \multirow[t]{2}{*}{2004} & $3,36 e-05$ & $3,54 \mathrm{e}-05$ & $3,33 e-05$ & $3,48 e-05$ \\
\hline & $(1,41 \mathrm{e}-05)^{\star \star}$ & $(1,40 e-05)^{\star \star}$ & $(1,37 e-05)^{\star \star}$ & $(1,56 e-05)^{\star \star}$ \\
\hline \multirow[t]{2}{*}{2005} & $4,20 e-05$ & 1,71e-05 & $3,32 \mathrm{e}-05$ & $4,57 e-05$ \\
\hline & $(2,73 e-05)$ & $(2,02 \mathrm{e}-05)$ & $(2,26 e-05)$ & $(2,63 e-05)^{\star}$ \\
\hline
\end{tabular}

\footnotetext{
17 En esta clasificación se utilizó el número total de distritos de 2011. No obstante, esta clasificación no tiene una diferencia notable con respecto a los 1.131 distritos considerados para ese año en los análisis posteriores.
} 
Cuadro 3 (continuación)

\begin{tabular}{|c|c|c|c|c|}
\hline & (1) & (2) & (3) & (4) \\
\hline \multirow[t]{2}{*}{2006} & 0,000151 & 0,000141 & 0,000137 & 0,000149 \\
\hline & $(3,48 \mathrm{e}-05)^{\star \star \star}$ & $(3,38 \mathrm{e}-05)^{\star \star \star}$ & $(3,34 \mathrm{e}-05)^{\star \star \star}$ & $(3,79 e-05)^{\star \star \star}$ \\
\hline \multirow[t]{2}{*}{2007} & 0,000166 & 0,000172 & 0,000135 & 0,000153 \\
\hline & $(3,24 \mathrm{e}-05)^{\star \star \star}$ & $(3,28 \mathrm{e}-05)^{\star \star \star}$ & $(3,36 e-05)^{\star \star \star}$ & $(3,96 e-05)^{\star \star \star}$ \\
\hline \multirow[t]{2}{*}{2008} & 0,000337 & 0,000345 & 0,000342 & 0,000378 \\
\hline & $(4,66 e-05)^{\star \star \star}$ & $(4,75 e-05)^{\star \star \star}$ & $(4,74 \mathrm{e}-05)^{\star \star \star}$ & $(5,70 \mathrm{e}-05)^{\star \star \star}$ \\
\hline \multirow[t]{2}{*}{2009} & 0,000206 & 0,000263 & 0,000202 & 0,000211 \\
\hline & $(5,88 \mathrm{e}-05)^{\star \star \star}$ & $(4,63 e-05)^{\star \star \star}$ & $(5,67 e-05)^{\star \star \star}$ & $(6,48 \mathrm{e}-05)^{\star \star \star}$ \\
\hline \multirow[t]{2}{*}{2010} & 0,000355 & 0,000277 & 0,000271 & 0,000276 \\
\hline & $(8,06 e-05)^{\star \star \star}$ & $(7,18 \mathrm{e}-05)^{\star \star \star}$ & $(7,18 \mathrm{e}-05)^{\star \star \star}$ & $(8,05 e-05)^{\star \star \star}$ \\
\hline \multirow[t]{2}{*}{2011} & 0,000386 & 0,000398 & 0,000450 & 0,000460 \\
\hline & $(7,28 \mathrm{e}-05)^{\star \star \star}$ & $(7,45 e-05)^{\star \star \star}$ & $(6,74 \mathrm{e}-05)^{\star \star \star}$ & $(7,82 \mathrm{e}-05)^{\star \star \star}$ \\
\hline \multirow[t]{2}{*}{ Interacción: g2²005 } & $3,84 \mathrm{e}-06$ & & $-9,45 e-06$ & $-1,04 \mathrm{e}-05$ \\
\hline & $(1,57 e-05)$ & & $(1,23 e-05)$ & $(1,18 \mathrm{e}-05)$ \\
\hline \multirow[t]{2}{*}{ Interacción: g2*2006 } & & $-1,23 e-05$ & $-1,55 e-05$ & $-1,65 e-05$ \\
\hline & & $(1,52 \mathrm{e}-05)$ & $(1,70 \mathrm{e}-05)$ & $(1,62 \mathrm{e}-05)$ \\
\hline \multirow[t]{2}{*}{ Interacción: g2*2007 } & & & $-1,73 e-05$ & $-1,17 e-05$ \\
\hline & & & $(1,72 \mathrm{e}-05)$ & $(1,68 \mathrm{e}-05)$ \\
\hline \multirow[t]{2}{*}{ Interacción: g2²009 } & $9,41 e-05$ & & $8,06 \mathrm{e}-05$ & 7,90e-05 \\
\hline & $(3,06 e-05)^{\star \star \star}$ & & $(3,26 e-05)^{\star \star}$ & $(3,22 \mathrm{e}-05)^{\star \star}$ \\
\hline \multirow[t]{2}{*}{ Interacción: g2*2010 } & & $-5,20 e-06$ & $-5,48 e-06$ & $-1,42 e-05$ \\
\hline & & $(3,80 e-05)$ & $(4,01 e-05)$ & $(3,80 e-05)$ \\
\hline \multirow[t]{2}{*}{ Interacción: g2*2011 } & & & $-6,82 e-05$ & $-7,44 \mathrm{e}-05$ \\
\hline & & & $(4,66 e-05)$ & $(4,58 \mathrm{e}-05)$ \\
\hline \multirow[t]{2}{*}{ Interacción: g3*2005 } & $-2,82 e-05$ & & $-1,88 e-05$ & $-2,49 e-05$ \\
\hline & $(1,54 \mathrm{e}-05)^{*}$ & & $(1,24 \mathrm{e}-05)$ & $(1,21 \mathrm{e}-05)^{\star \star}$ \\
\hline \multirow[t]{2}{*}{ Interacción: g3²006 } & & $-1,43 e-05$ & $4,68 \mathrm{e}-06$ & $1,20 \mathrm{e}-06$ \\
\hline & & $(1,51 \mathrm{e}-05)$ & $(1,64 \mathrm{e}-05)$ & $(1,54 \mathrm{e}-05)$ \\
\hline \multirow[t]{2}{*}{ Interacción: g3²007 } & & & $4,39 e-05$ & $6,13 e-05$ \\
\hline & & & $(2,10 \mathrm{e}-05)^{\star \star}$ & $(2,12 \mathrm{e}-05)^{\star \star \star}$ \\
\hline \multirow[t]{2}{*}{ Interacción: g3²009 } & 0,000132 & & 0,000142 & 0,000138 \\
\hline & $(2,75 e-05)^{\star \star \star}$ & & $(2,99 e-05)^{\star \star \star}$ & $(2,91 \mathrm{e}-05)^{\star \star *}$ \\
\hline \multirow[t]{2}{*}{ Interacción: g3*2010 } & & 1,02e-05 & $3,20 \mathrm{e}-05$ & 2,27e-05 \\
\hline & & $(3,74 \mathrm{e}-05)$ & $(3,93 e-05)$ & $(3,74 \mathrm{e}-05)$ \\
\hline \multirow[t]{2}{*}{ Interacción: g3*2011 } & & & $-3,10 e-06$ & $-1,15 e-05$ \\
\hline & & & $(4,54 \mathrm{e}-05)$ & $(4,43 e-05)$ \\
\hline \multirow[t]{2}{*}{ Interacción: g4*2005 } & $-1,24 \mathrm{e}-05$ & & $-9,64 e-06$ & $-1,73 e-05$ \\
\hline & $(1,61 e-05)$ & & $(1,38 \mathrm{e}-05)$ & $(1,36 e-05)$ \\
\hline \multirow[t]{2}{*}{ Interacción: g4*2006 } & & $1,49 e-06$ & $2,78 \mathrm{e}-06$ & $5,43 e-06$ \\
\hline & & $(1,47 e-05)$ & $(1,52 \mathrm{e}-05)$ & $(1,46 e-05)$ \\
\hline Interacción: g4*2007 & & & $4,25 e-05$ & 8,07e-05 \\
\hline & & & $(2,31 \mathrm{e}-05)^{\star}$ & $(2,32 \mathrm{e}-05)^{\star \star \star}$ \\
\hline Interacción: g4²009 & 8,46e-05 & & 8,90e-05 & $9,31 e-05$ \\
\hline & $(3,25 e-05)^{\star \star \star}$ & & $(3,54 \mathrm{e}-05)^{\star \star}$ & $(3,48 \mathrm{e}-05)^{\star \star \star}$ \\
\hline Interacción: g4²010 & & 8,76e-05 & $9,04 \mathrm{e}-05$ & $9,51 e-05$ \\
\hline & & $(3,61 e-05)^{\star \star}$ & $(3,90 \mathrm{e}-05)^{\star \star}$ & $(3,72 \mathrm{e}-05)^{\star \star}$ \\
\hline Interacción: g4²011 & & & $-0,000107$ & $-0,000104$ \\
\hline & & & $(4,70 \mathrm{e}-05)^{\star \star}$ & $(4,56 e-05)^{\star \star}$ \\
\hline Interacción: g5*2005 & $-0,000103$ & & $-5,21 e-05$ & $-6,15 e-05$ \\
\hline & $(3,13 e-05)^{\star \star \star}$ & & $(2,05 e-05)^{\star \star}$ & $(2,19 \mathrm{e}-05)^{\star \star \star}$ \\
\hline Interacción: g5²006 & & 0,000102 & $9,12 \mathrm{e}-05$ & 0,000111 \\
\hline & & $(3,32 \mathrm{e}-05)^{\star \star \star}$ & $(3,76 e-05)^{\star \star}$ & $(3,93 e-05)^{\star \star \star}$ \\
\hline
\end{tabular}


Cuadro 3 (conclusión)

\begin{tabular}{lcccc}
\hline & $(1)$ & $(2)$ & $(3)$ & $(4)$ \\
\hline Interacción: 95*2007 & & & 0,000105 & 0,000254 \\
\hline & & & $(3,90 \mathrm{e}-05)^{\star \star \star}$ & $(4,68 \mathrm{e}-05)^{\star \star \star}$ \\
\hline Interacción: 95*2009 & $-7,62 \mathrm{e}-05$ & & $-1,93 \mathrm{e}-05$ & $5,25 \mathrm{e}-05$ \\
\hline & $(0,000112)$ & & $(9,25 \mathrm{e}-05)$ & $(7,35 \mathrm{e}-05)$ \\
\hline Interacción: g5*2010 & & 0,000356 & 0,000345 & 0,000405 \\
\hline & & $(9,52 \mathrm{e}-05)^{\star \star \star}$ & $(0,000101)^{\star \star \star}$ & $(0,000107)^{\star \star \star}$ \\
\hline Interacción: g5*2011 & & $-0,000117$ & $-5,71 \mathrm{e}-05$ \\
\hline Constante & & & $(0,000104)$ & $(0,000114)$ \\
\hline & 0,000190 & 0,000103 & 0,000152 & $-3,00 \mathrm{e}-05$ \\
\hline Observaciones & $(0,000328)$ & $(0,000338)$ & $(0,000338)$ & $(0,000388)$ \\
\hline R-cuadrado & 11,310 & 11,310 & 11,310 & 11,310 \\
\hline Fuente: & 0,450 & 0,454 & 0,456 & 0,423 \\
\hline
\end{tabular}

Fuente: Elaboración propia

Nota: Los errores estándar robustos figuran entre paréntesis. * denota significancia al $10 \%$, ** significancia al $5 \%$ y *** significancia al $1 \%$.

En la segunda columna se consideran las interacciones en los años electorales. En ambos ciclos electorales (2006 y 2010) el efecto incremental es positivo y significativo en las municipalidades del grupo 5 (el que recibe un mayor volumen de canon). Ello quiere decir que el efecto de las transferencias por canon en el gasto de capital se acentúa en los años electorales en el $20 \%$ de las municipalidades que reciben mayores transferencias.

Cabe resaltar que, aparte del grupo 5, solo el grupo 4 presenta coeficientes positivos en ambos ciclos electorales. En los demás grupos el signo es negativo. Estos resultados apoyarían la hipótesis de la existencia de un ciclo político presupuestal en las municipalidades receptoras de mayores montos de canon minero.

Para asegurar la solidez de los resultados, en la tercera especificación se incluyeron variables multiplicativas en los años previo y posterior a las elecciones. Se confirma que, en el año electoral, el efecto incremental es positivo y significativo solo para el grupo que recibe mayores montos de canon en ambas elecciones, y para el grupo 4 en las elecciones de 2010.

\section{Conclusiones}

En este estudio se evalúa la importancia del ciclo político presupuestal y su interacción con el canon minero en la ejecución del gasto de capital de las municipalidades distritales del Perú. Este es uno de los pocos estudios que analiza la ciclicidad de la ejecución del gasto público a nivel subnacional y su relación con las transferencias recibidas producto de la explotación de recursos mineros en el Perú.

Los primeros resultados muestran que, en términos generales, no existe una marcada ciclicidad entre el gasto de capital de las municipalidades y los años electorales. Las estimaciones de las variables ficticias por año señalan que, en promedio, en 2006 y 2010 el gasto de capital aumentó un $37,1 \%$ con respecto al año anterior (2005 y 2009, respectivamente). Sin embargo, también hubo un incremento posterior a las elecciones, de alrededor del 4,6\% (en 2007 y 2011). Además, los montos transferidos por concepto de canon minero tienen un efecto positivo y significativo en el gasto de capital de 2006. No obstante, en promedio, su efecto en el ciclo político presupuestal es marginal. Así, un incremento de las transferencias de canon minero per cápita da lugar a un menor aumento del gasto de capital per cápita en 2010 en comparación con 2006. 
Al separar los municipios según el volumen de canon recibido, se observa que solo el grupo que recibe una mayor cantidad de canon minero realiza un incremento significativo adicional en el gasto de capital en los dos años electorales. Es decir, solamente en el grupo que recibe un mayor volumen de canon minero el gasto de capital se incrementa significativamente en los años electorales.

\section{Bibliografía}

Akhmedov, A., A. Ravichev y E. Zhuravskaya (2002), "Opportunistic Political Cycles: Test in a Young Democracy Setting" [en línea] http://pdc.ceu.hu/archive/00001617/.

Aragón, F. y C. Casas (2009), "Capacidades técnicas y gasto local: el caso de las municipalidades peruanas", Perspectivas. Análisis de temas críticos para el desarrollo sostenible, vol. 7, № 1, Corporación Andina de Fomento (CAF).

Aragón, F. y J. P. Rud (2013), "Natural resources and local communities: evidence from a Peruvian gold mine", American Economic Journal: Economic Policy, vol. 5, № 2, Nashville, Tennessee, American Economic Association.

(2010), "¿Éxito en la sostenibilidad fiscal? El caso de Perú", ¿Quiénes deciden el presupuesto? La economía política del proceso presupuestario en América Latina, E. Stein, M. Hallerberg y C. Scartascini (eds.), Washington, D.C., Banco Interamericano de Desarrollo (BID).

Auty, R. (1990), Resource-based Industrialization: Sowing the Oil in Eight Developing Countries, Nueva York, Oxford University Press.

Bravo-Ortega, C. y J. de Gregorio (2005), "The relative richness of the poor? Natural resources, human capital, and economic growth”, Policy Research Working Paper, № 3484, Washington, D.C., Banco Mundial.

Brunnschweiler, C. (2008), "Cursing the blessings? Natural resource abundance, institutions and economic growth", World Development, vol. 36, № 3, Amsterdam, Elsevier.

Carranza, L., J. Chávez y J. Valderrama (2006), La economía política del proceso presupuestario: el caso peruano, Washington, D.C., Banco Interamericano de Desarrollo (BID).

Collier, P. (2010), "The political economy of natural resources", Social Research, vol. 77, № 4.

Collier, P. y B. Goderis (2007), "Commodity prices, growth, and the natural resource curse: reconciling a conundrum", Working Paper, № 2007-15, Universidad de Oxford.

Contraloría General de la República (2011), Distribución y utilización de los recursos del canon, sobrecanon, fondo de desarrollo socioeconómico del proyecto Camisea y regalía minera en el Perú, Lima.

Deacon, R. T. (2011), "The political economy of the natural resource curse: a survey of theory and evidence", Foundations and Trends in Microeconomics, vol. 7, № 2.

Drazen, A. y M. Eslava (2008), "Electoral manipulation via voter-friendly spending: theory and evidence", borrador.

(2005), "Electoral manipulation via expenditure composition: theory and evidence", NBER Working Paper, $N^{\circ} 11085$, Cambridge, Massachusetts, Oficina Nacional de Investigaciones Económicas.

Gajate-Garrido, G. (2013), "Excluding the rural population: the impact of public expenditure on child malnutrition in Peru", Policy Research Working Paper, №6666, Washington, D.C., Banco Mundial.

Gámez, C. y A. Ibarra-Yúnez (2007), "El ciclo político oportunista y el gasto de los estados mexicanos”, Gestión y Política Pública, vol. 18, № 1, Ciudad de México, Centro de Investigación y Docencia Económicas.

Gelb, A. y otros (1988), Oil Windfalls: Blessing or Curse, Nueva York, Oxford University Press.

Gylfason, T. (2001), "Natural resources, education and economic development", European Economic Review, vol. 45, № 4-6, Amsterdam, Elsevier.

Hausmann, R. y R. Rigobon (2002), "An alternative interpretation of the 'resource curse': theory and policy implications", NBER Working Paper, № 9424, Cambridge, Massachusetts, Oficina Nacional de Investigaciones Económicas.

Isham, J. y otros (2005), "The varieties of resource experience: natural resource export structures and the political economy of economic growth", World Bank Economic Review, vol. 19, № 2, Washington, D.C., Banco Mundial.

Manzano, O. y R. Rigobon (2001), "Resource curse or debt overhang?", NBER Working Paper, № 8390, Cambridge, Massachusetts, Oficina Nacional de Investigaciones Económicas. 
Monteiro, J. (2009), "Resource Booms and Politics: The Effects of Oil Shocks on Public Goods and Elections [en línea] http://www.caf.com/attach/19/default/oil_politics_caf.pdf.

Monteiro, J. y C. Ferraz (2012), "Does Oil Make Leaders Unaccountable? Evidence from Brazil's offshore oil boom" [en línea] http://www.unamur.be/en/eco/eeco/pdf/OilPaper2012-05.pdf.

Robinson, J. A., R. Torvik y T. Verdier (2005), "Political foundations of the resource curse", Universidad de Ciencia y Tecnología de Noruega [en línea] http://www.svt.ntnu.no/iso/ragnar.torvik/bardhanjde.pdf.

Rogoff, K. (1990), "Equilibrium political budget cycles", American Economic Review, vol. 80, № 1, Nashville, Tennessee, American Economic Association.

Rogoff, K. y A. Sibert (1988), "Elections and macroeconomic policy cycles", The Review of Economic Studies, vol. 55, No 1, Oxford University Press.

Sachs, J. y A. Warner (2001), "The curse of natural resources", European Economic Review, vol. 45, № 4-6, Amsterdam, Elsevier.

(1997), "Natural Resource Abundance and Economic Growth", Cambridge, Massachusetts, Universidad de Harvard [online] http://citeseerx.ist.psu.edu/viewdoc/download?doi=10.1.1.422.8285\&rep=rep1\&type=pdf. (1995), "Natural resource abundance and economic growth", NBER Working Paper, № 5398, Cambridge, Massachusetts, Oficina Nacional de Investigaciones Económicas.

Sanguinetti, P. (2010), "Canon minero y decisiones fiscales subnacionales en el Perú", Documentos de Trabajo, N²010/01 [en línea] https://www.caf.com/media/3180/201001SanguinettiFebrero2010.pdf.

Shi, M. y J. Svensson (2006), "Political budget cycles: do they differ across countries and why?", Journal of Public Economics, vol. 90, № 8-9, Amsterdam, Elsevier.

_(2001), "Conditional political budget cycles", CEPR Discussion Paper, № 3352 [en línea] http://people. su.se/ jsven/pbc.pdf. 


\section{Anexo A1}

\section{Cuadro A1.1}

Categorías de las municipalidades distritales según el monto de canon minero recibido en 2011

(En millones de nuevos soles)

\begin{tabular}{lllll}
\hline Categoría & & & & \\
\hline 1 & de & 0,000 & a & 0,007 \\
\hline 2 & de & 0,007 & a & 0,098 \\
\hline 3 & de & 0,098 & a & 0,466 \\
\hline 4 & de & 0,466 & a & 1,549 \\
\hline 5 & de & 1,549 & a & más \\
\hline
\end{tabular}

Fuente: Elaboración propia.

Nota: En la clasificación por quintiles se utilizó el número total de distritos según el canon recibido en 2011.

\section{Gráfico A1.1}

Evolución del gasto de capital ejecutado por las municipalidades distritales según su categoría (2002-2011)

(En millones de nuevos soles)

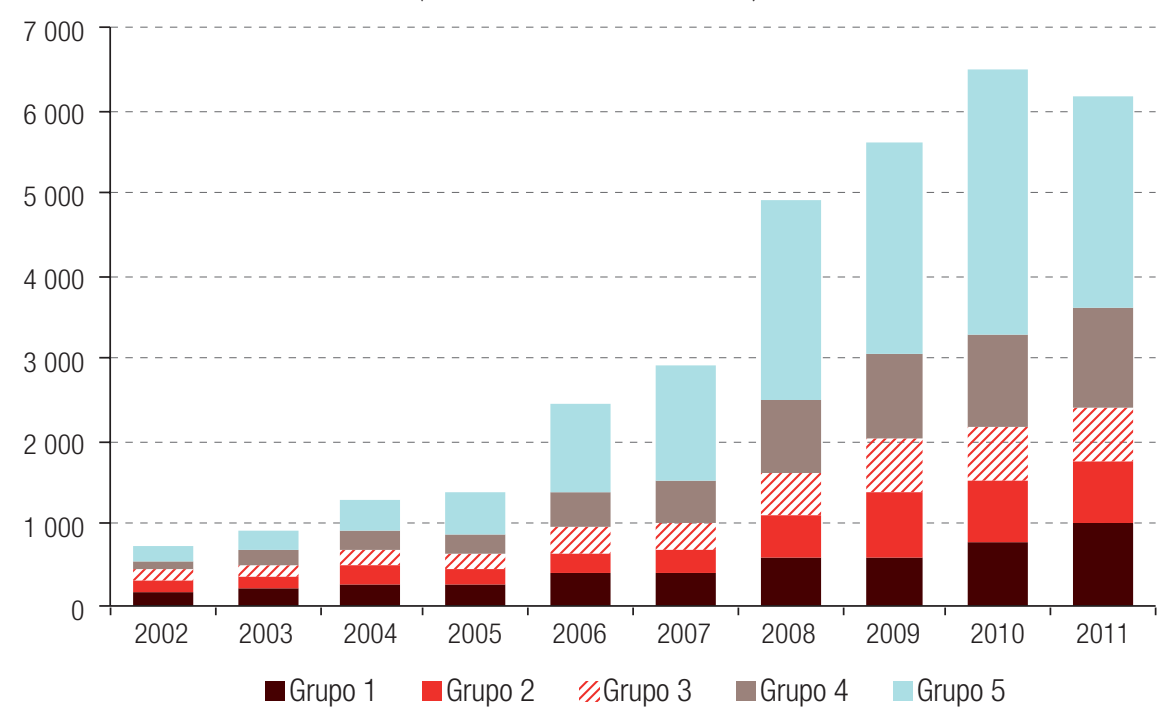

Fuente: Elaboración propia, sobre la base de datos del Ministerio de Economía y Finanzas (MEF).

Nota: En la clasificación por quintiles se utilizó el número total de distritos según el canon recibido en 2011.

\section{Cuadro A1.2}

Evolución del crecimiento del gasto de capital en las municipalidades distritales según los grupos de canon

(En porcentajes)

\begin{tabular}{lccrrrrrrr}
\hline Crecimiento anual & 2003 & 2004 & 2005 & 2006 & 2007 & 2008 & 2009 & 2010 & 2011 \\
\hline Grupo 1 & 34 & 21 & -3 & 62 & -1 & 55 & 1 & 28 & 28 \\
\hline Grupo 2 & 10 & 37 & -17 & 34 & 16 & 73 & 48 & -3 & 4 \\
\hline Grupo 3 & 9 & 52 & -7 & 62 & 8 & 63 & 25 & 0 & 4 \\
\hline Grupo 4 & 15 & 56 & 9 & 71 & 19 & 60 & 21 & 9 & 4 \\
\hline Grupo 5 & 34 & 55 & 36 & 109 & 28 & 78 & 4 & 27 & -20 \\
\hline Total & 21 & 43 & 8 & 77 & 18 & 70 & 13 & 17 & -5
\end{tabular}

Fuente: Elaboración propia.

Nota: En la clasificación por quintiles se utilizó el número total de distritos según el canon recibido en 2011. 


\section{Anexo A2}

Cuadro A2.1

Metodología de distribución del canon minero

\begin{tabular}{|c|c|c|c|}
\hline & Porcentaje & Receptor & Criterio de distribución \\
\hline \multirow{5}{*}{$\begin{array}{l}\text { Canon minero } \\
\text { (50\% del impuesto } \\
\text { sobre la renta de las } \\
\text { empresas mineras) }\end{array}$} & $10 \%$ & $\begin{array}{l}\text { Municipios distritales donde se } \\
\text { explotan los recursos }\end{array}$ & $\begin{array}{l}\text { Si existe más de una municipalidad, } \\
\text { se repartirá en partes iguales. }\end{array}$ \\
\hline & $25 \%$ & $\begin{array}{l}\text { Municipios distritales de la provincia } \\
\text { donde se explotan los recursos }\end{array}$ & $\begin{array}{l}\text { Según la población y las necesidades } \\
\text { básicas insatisfechas. }\end{array}$ \\
\hline & $40 \%$ & $\begin{array}{l}\text { Municipios provinciales del departamento } \\
\text { donde se explotan los recursos }\end{array}$ & $\begin{array}{l}\text { Según la población y las necesidades } \\
\text { básicas insatisfechas. }\end{array}$ \\
\hline & $20 \%$ & Gobierno regional & \\
\hline & $5 \%$ & Universidades nacionales & \\
\hline
\end{tabular}

Fuente: Elaboración propia, sobre la base de datos del Ministerio de Economía y Finanzas, Metodología de distribución. 


\section{Anexo A3}

Cuadro A3.1

Descripción de las variables de la muestra para el modelo de ciclo político presupuestal

\begin{tabular}{lcccrcr}
\hline Variable & Distritos & Años & Media & $\begin{array}{r}\text { Desviación } \\
\text { estándar }\end{array}$ & Mínimo & Máximo \\
\hline Tasa de analfabetismo departamental & 1131 & 10 & 0,1211 & 0,0603 & 0,0228 & 0,2790 \\
\hline $\begin{array}{l}\text { Proporción de población } \\
\text { rural departamental }\end{array}$ & 1131 & 10 & 0,4161 & 0,2241 & 0,0000 & 0,8368 \\
\hline Número de emergencias por provincia & 1131 & 10 & 28,3321 & 45,8182 & 0,0000 & 271,0000 \\
\hline Número de años en el cargo & 1131 & 10 & 2,9435 & 1,6953 & 1,0000 & 9,0000 \\
\hline $\begin{array}{l}\text { Gasto de capital per cápita en } \\
\text { millones de nuevos soles }\end{array}$ & 1131 & 10 & 0,0004 & 0,0008 & 0,0000 & 0,0254 \\
\hline $\begin{array}{l}\text { Ingreso PIM per cápita en } \\
\text { millones de nuevos soles }\end{array}$ & 1131 & 10 & 0,0007 & 0,0021 & 0,0000 & 0,0944 \\
\hline $\begin{array}{l}\text { Canon minero per cápita en } \\
\text { millones de nuevos soles }\end{array}$ & 1131 & 10 & 0,0002 & 0,0013 & 0,0000 & 0,0470 \\
\hline $\begin{array}{l}\text { Canon minero en millones } \\
\text { de nuevos soles }\end{array}$ & 1131 & 10 & 1,1613 & 8,5546 & 0,0000 & 476,9459 \\
\hline
\end{tabular}

Fuente: Elaboración propia.

Cuadro A3.2

Descripción de la muestra para el modelo de organizaciones políticas, 2002, 2006 y 2010

\begin{tabular}{lccrrrr}
\hline Variable & Distritos & Años & \multicolumn{1}{c}{ Media } & $\begin{array}{c}\text { Desviación } \\
\text { estándar }\end{array}$ & \multicolumn{1}{c}{ Mínimo } & \multicolumn{1}{c}{ Máximo } \\
\hline Tasa de analfabetismo departamental & 1131 & 3 & 0,1000 & 0,1000 & 0,0000 & 0,3000 \\
\hline Nivel de pobreza departamental & 1131 & 3 & 51,2000 & 19,8000 & 8,7000 & 88,7000 \\
\hline Número de emergencias por provincia & 1131 & 3 & 24,5000 & 43,2000 & 0,0000 & 271,0000 \\
\hline $\begin{array}{l}\text { Ingreso según el presupuesto inicial } \\
\text { modificado en millones de nuevos soles }\end{array}$ & 1131 & 3 & 4,8000 & 16,3000 & 0,2000 & 431,1000 \\
\hline $\begin{array}{l}\text { Canon minero en millones } \\
\text { de nuevos soles }\end{array}$ & 1131 & 3 & 0,9000 & 8,7000 & 0,0000 & 424,9000 \\
\hline Población & 1131 & 3 & 14704,4000 & 49909,6000 & 184,0000 & 983095,0000 \\
\hline
\end{tabular}

Fuente: Elaboración propia.

Cuadro A3.3

Descripción de la muestra para el modelo de organizaciones políticas, 2006 y 2010

\begin{tabular}{lcrrrrr}
\hline Variable & Distritos & Años & \multicolumn{1}{c}{ Media } & $\begin{array}{r}\text { Desviación } \\
\text { estándar }\end{array}$ & \multicolumn{1}{c}{ Mínimo } & \multicolumn{1}{c}{ Máximo } \\
\hline Tasa de analfabetismo departamental & 1131 & 2 & 0,1000 & 0,1000 & 0,0000 & 0,2000 \\
\hline Nivel de pobreza departamental & 1131 & 2 & 46,2000 & 19,9000 & 8,7000 & 88,7000 \\
\hline Número de emergencias por provincia & 1131 & 2 & 31,4000 & 49,5000 & 0,0000 & 271,0000 \\
\hline $\begin{array}{l}\text { Ingreso según el presupuesto inicial } \\
\text { modificado en millones de nuevos soles }\end{array}$ & 1131 & 2 & 6,3000 & 19,3000 & 0,3000 & 431,1000 \\
\hline $\begin{array}{l}\text { Canon minero en millones } \\
\text { de nuevos soles }\end{array}$ & 1131 & 2 & 1,4000 & 10,7000 & 0,0000 & 424,9000 \\
\hline Población & 1131 & 2 & 15126,2000 & 51910,5000 & 184,0000 & 983095,0000 \\
\hline
\end{tabular}

Fuente: Elaboración propia. 